\title{
MANIPULATIVE SPEECH: A THEORETICAL OVERVIEW
}

\author{
Seda Gasparyan* \\ Rafayel Harutyunyan** \\ Yerevan State University
}

\begin{abstract}
Manipulation is one of the concepts that needs a more in-depth theoretical and practical examination. It is employed in many areas of life, including personal and social matters, intellectual and professional pursuits, and, of course, politics. This paper is an approach, the purpose of which is to study through comparativecontrastive, inductive, deductive and observation methods the concept of manipulation as a psychological and linguistic phenomenon where the central emphasis is on the manipulative techniques and tactics that are utilized for various reasons such as illegitimate domination and social abuse. At this level of investigation we find it essential to illustrate different approaches to the study of this phenomenon as well as certain dictionary definitions to be able to fully perceive and comprehend the properties of manipulation.
\end{abstract}

Keywords: manipulation, linguistic and psychological manipulation, social abuse, manipulative strategies, propaganda, political discourse.

\section{Introduction}

The objective of the present research being the study of different approaches to manipulation in speech, in this paper we compare the manipulative strategies and techniques elaborated by different scholars in the literature of the question. To achieve the goal of determining the differences and similarities between various approaches, at the present stage of investigation the following methods of analysis are used: the method of observation, as well as comparativecontrastive, inductive, deductive analyses.

Manipulation is one of the phenomena that are highly affected by propaganda and closely related to media and political discourses. The term manipulation derives from the Latin word manipulus meaning handful, bundle, which in its turn comes from the words manus (hand) and pleo (to fill). The

\footnotetext{
*sedagasparyan@ysu.am

** rafayel.harutyunyan22@gmail.com
}

This work is licensed under a Creative Commons Attribution-NonCommercial 4.0 International License.
Received: 25.08.2021

Revised: 01.10 .2021

Accepted: 08.10.2021

(C) The Author(s) 2021 
explanations of the concept of manipulation are formulated differently in different dictionaries, and they stress out different aspects of the notion ${ }^{1}$, however, all of them are based on the essential idea of managing and controlling people's thoughts and behaviours by using unfair and abusive tactics.

The concept of manipulation has been developed by many researchers, and in all the existing investigations the common thread of the social nature of manipulation the accomplishment of which violates social norms, runs through different theories. According to Joseph Raz, (1986, pp. 377-379) "manipulation, unlike coercion, does not interfere with a person's alternatives". Instead, it perverts how a person makes judgments, establishes preferences, or sets goals. Anne Barnhill (2014) as well as Cass R. Sunstein (2015, p. 12) believe, that manipulation is "directly influencing someone's beliefs, desires, or feelings, so that she falls short of ideals for belief, desire, or emotion in ways that are generally not in her self-interest or are likely not in her self-interest in the present context." In Wilkinson's words (2013, p. 341), "being controlled might be regarded informally as being made someone's puppet on a string".

In their attempt to understand the peculiar features of manipulation Ruth Faden and Tom Beauchamp (1986, p. 354-368) have come to the conclusion that of particular interest is psychological manipulation which is done through "any purposeful act that successfully affects a person to believe or action by inducing changes in mental processes other than those involved in understanding".

All these definitions give rise to the assumption that manipulation is not only a strategy for achieving one's own objectives by fooling others and convincing them of things that are not necessarily true, but are also used to gain people's trust by concealing some facts about reality, i.e. misrepresenting the truth.

Against the background of what has been said above, we can take into account that manipulation as a strategy is a persuasion tactic frequently used to convey a specific message whose major goal is to influence the audience and persuade them to support the manipulator's views or actions. It follows logically that manipulation, on the other hand, is a psycholinguistic process. Hence, it is impossible to come to any definite conclusion on this point without integrating the results of psychological and linguistic research.

Manipulation and manipulators are largely conditioned by each other. It seems essential to emphasize that manipulators are aware of their targets' weak 
points and utilize those vulnerabilities as their primary tool to play with the strings of the person's emotions and sentiments. They are rather clever, and having mastered the psychology of human behavior, as well as the art of rhetorical persuasion, they are capable of persuading huge crowds for their own good (Gasparyan et al., 2019, p. 45). These individuals are naturally dominating, and they are typically in charge of everything in partnerships. Manipulators are more powerful and often hold positions of control. Their primary objective is to influence others' behaviour, emotions, and analytical thinking without considering that their wish may not coincide to the desire of the manipulated. They trick the manipulated into believing that the latter, the dubbed victims, lack the ability to consider and weigh things for themselves.

We can see that each of the above interpretations is similar to the other, with the motive for manipulating being nearly always the same in every case to make people do what you want by influencing their ideas and mind while still giving choices for them to select from. The manipulator achieves this impact by employing a variety of methods, including distraction, seduction, misdirection, and reasonable reasoning, to mention a few (Handelman, 2009, p. 11). The manipulator diverts the target's attention away from the main issue by making false statements or providing blurry and ambiguous information. Thus, the core information conveyed by the manipulator is presented through seemingly rational arguments, which, in other circumstances would not be approved by the target, especially if the manipulator were much fairer and provided all the facts as they are.

\section{Techniques and tactics for making manipulative intentions come to life}

In his work How to successfully handle manipulative people Preston Ni (2014) characterizes psychological manipulation as the use of undue influence, such as mental distortion and emotional exploitation, to acquire power, control, rewards, and/or privileges at the expense of the victim. The author also makes a further point about the distinction of social influence from psychological manipulation. It is stated that normally, most people experience healthy social influence in positive interactions, meanwhile many individuals are used for the benefit of others through psychological manipulation. In addition, the author mentions one of the important components of successful psychological manipulation when the manipulator purposefully establishes a power imbalance and uses the victim to further his/her agenda. The author draws attention to the significance of the four common characteristics a manipulative individual can 
have. For him, it is so important to be aware of the fact that a manipulator usually knows how to detect his target's weaknesses, and the moment they are found, they are undoubtedly used against the latter. Another characteristic feature of an individual with manipulative intentions is the ability to convince the target through shrewd machinations to give up something of himself/herself and serve the self-centered interests of the manipulator, and when the latter succeeds in taking advantage of the target, s/he will likely repeat the violation, until the target becomes aware of the exploitation and puts a stop to it. These traits are often flexibly switched up to fit the needs of the manipulator. Consequently, Ni claims it more suitable to highlight the following categories of psychological manipulation: negative manipulation which is designed to make the victim feel inferior, inadequate, insecure, and/or self-doubting, and this gives the manipulator a chance to obtain superiority; positive manipulation, intended to emotionally entice the victim in exchange for favours, concessions, sacrifices, or promises; deception and intrigue that are usually meant to enchant, awaken the curiosity or attention of the victim and alter his/her perception in order to gain more power; display of strategic helplessness, aimed at taking advantage of the victim's good will, guilty conscience, sense of responsibility, obligation and inclination to protect and nurture (Ni, 2014, pp. 5-6).

Proceeding from these classifications and considering the fact of frequent employment of coercion by manipulators to force others into a disadvantageous situation, Ni proposes fourteen tactics:

1. Home court advantage is a tactic which provides a manipulator more comfort in exerting greater power and control over the manipulated. The manipulator insists on meeting and talking with the target in a physical location that is preferable for him/her (that may be the manipulator's office, house, car, or any other place where s/he may exert greater power and control as he feels more protected and confident, whereas the target does not).

2. The manipulator may let the target speak first to establish the baseline of his/her talk and look for weakness. This technique is often applied by salespeople by asking the target general and probing questions and establishing a baseline about his/her thinking and behaviour. This gives the manipulator a chance to analyse the strengths of the target and the limits of his/her possible actions. This type of inquiry with a concealed goal may occur in both commercial and personal interactions.

3. Manipulation of facts presupposes lying, excuse-making, being hypocritical, making the victims feel responsible for their own victimization, 
and distorting the truth through disclosing or withholding the key information. In the employment of this tactic, exaggeration and understatement are often applied as strategic components.

4. Overwhelming the target with facts and statistics which $\mathrm{s} /$ he may not be aware of is practiced by people who pretend to be the most knowledgeable and talented and enjoy "intellectual bullying". This may happen in sales and financial circumstances, as well as professional talks and negotiations, social and relationship disputes when by exerting expert control over the target, the manipulator, hoping to have established his/her intellectual superiority, tries to persuade the target to embrace the manipulator's purpose.

5. Overwhelming the target with procedures and red tape is a technique used to defer fact-finding and truth-seeking, hide faults and vulnerabilities, and thus escape scrutiny. This is accomplished through utilizing bureaucracy, processes, regulations and bylaws, committees, and other hurdles to maintain the manipulator's power and position while making the life of the target more difficult.

6. During arguments, some individuals raise their voices and display unpleasant feelings. To increase effect, they project their voice loudly enough and accompany their anger by powerful body language, such as standing or passionate motions. If they do it on purpose making the target cave into their pressure and give them what they want, they in fact accomplish a kind of aggressive manipulation which $\mathrm{Ni}$ describes as raising their voice and displaying negative emotions.

7. Negative surprise is also a manipulative tactic implemented in speech for throwing the target off and gaining a psychological edge. This might range from lowballing in a negotiation to declaring outright that the target will be unable to follow through and deliver in some way. The unexpected unfavorable information usually comes without warning, giving him/her little time to prepare and respond.

8. Giving no time or little time to decide is a technique often employed in classic sales and negotiation in which the manipulator forces the manipulated to make a decision before they are ready. It is thought that by exerting tension and control to the manipulated, the latter will crack and give in to the aggressor's demands.

9. Negative humor designed to poke at the targets weaknesses is sure to disempower him/her. Manipulators sometimes veil their critical comments as comedy or sarcasm in order to give rise to inferiority and insecurity in the 
target. Comments on the target's appearance, the older model of his/her smartphone, the background and credentials, or the fact that the latter arrived two minutes late and out of breath are all possible examples.

10. Consistently judging and criticizing the target to make him/her feel inadequate is a tool in the hands of the manipulator to behave explicitly. Keeping the target off-balance, the manipulator maintains supremacy by constantly marginalizing, insulting, and rejecting him/her. Avoiding true and constructive answers or significant methods to assist the target, the manipulator intentionally creates the idea that there is always something wrong with him/her and the latter is never good enough.

11. When the manipulator purposefully does not respond to the legitimate calls, text messages, emails, or other questions of the target, this silent treatment becomes a powerful psychological technique of manipulation which instills doubt and confusion in the mind of the target, thus increasing the influence of the manipulator on the target.

12. Another interesting manipulative trick on the list of Ni's manipulative tactics is the so-called pretended ignorance which is a typical example of acting stupid when the manipulator pretends s/he does not comprehend what is wanted $\mathrm{him} / \mathrm{her}$ to do. This trick is the kids' favorite and they constantly try to make use of it in their relations with adults.

13. As already mentioned above, the recipient's weak areas are constantly being targeted by a manipulator who often tries to hold someone else accountable for his/her pleasure, success, or failings. The manipulator coerces the target into granting unreasonable requests and demands by using the emotional vulnerabilities and susceptibility of the latter through guilt baiting which the manipulator believes to be more rational and effective than straightforward blaming.

14. Intentional exaggeration or fabrication of personal difficulties or weaknesses, playing a helpless victim in order to garner compassion and favour is also considered a manipulative tactic described by $\mathrm{Ni}$ as victimhood. This is practiced to take advantage of the victim's goodness, guilty conscience, feeling of responsibility and obligation, or protective and nurturing instincts in order to extract disproportionate advantages and concessions (Ni, 2015).

Another important investigation of the notion of manipulation and its realization in speech is presented in the book Dealing with manipulative people by George K. Simon (2020, p. 125) where the author holds the interest of the reader by suggesting some "tips for avoiding the traps of a manipulator". 
According to Simon, it is important to be aware of the telltale signs of character disturbance and the manipulative tactics, for this will be a good defense against manipulators who are ready to mislead, exploit, con, or otherwise hoodwink. The author singles out the following three tips: knowing the kind of persons one is dealing with; educating oneself about manipulative tactics; divesting oneself of harmful misconceptions. These tips let us understand that for getting a sense of someone's core nature one needs to keep an eye out for some personality traits, for knowing the difference between someone's basic personality or style of relating, i.e., their distinctive manner of perceiving and interacting with the world is of very good help.

It seems of utmost necessity to mention that skilled manipulators can use just about any behavior to con and deceive, and therefore it will be useful to draw a clear line between the manipulative tactics the author neatly presents:

1. evasion and diversion which manipulators use by answering the questions for short, i.e., giving answers that are not complete. The target needs to think about it for a while to understand that if someone appears to be sidestepping or bypassing a problem in some way, avoiding a topic, or refusing full transparency it does not mean they merely are nervous or justifiably cautious or guarded. They might be purposefully evasive in order to manipulate, particularly that manipulators are very skilled at shifting the target's attention to something unexpected, and diverting the focus of interest.

2. distortions, inconsistencies, and calculation of domissions, which are most successful when subtle and hidden, and are effective methods for someone to lie. Hence, manipulate in this case is to repeat a number of totally factual, verifiable facts while purposefully leaving out a critical piece of information that would cast an altogether different light on things.

3. rationalizations and excuses is a tactic which is employed by some individuals who appear to have an answer for everything, but all of a sudden, their explanations no longer make sense. Thus, it is very important to be cautious when someone explains events or gives justifications for doing particular things, and not to take everything at their face value. Otherwise stated, when things do not appear to add together, one needs to trust his/her intuition. There is no need to be scared of asking clarifying questions. However, creative excuse making may also be a totally intentional and deliberate technique to make one believe a person does not do anything wrong or has a just cause to do something that appears wrong, or has too many answers for actions that one finds disturbing in any manner. 
4. minimization and magnifying is a tactic that is normally used to minimize or magnify the effect of information, dependent on the purpose of the manipulator. This strategy is more widely used in business performances.

5. aiming to gain the target's trust manipulators skillfully turn on their charm to achieve their goal, for they know very well that seduction is one of the reliable tactics in the pursuit of their objective. The more cunning a manipulator is, and the keener he/she is on taking advantage of the target through deceiving them, the more cautious they are about currying their favour. At times, of course, the manipulator may look extremely real, however an experienced observer can see right through the deception.

6. conscientious people desire to do things right, and if someone invites them to feel guilty about doing or failing to do something, or humiliated about what they have done, they are more likely to be driven to put things right. When the intended target of manipulation has a well-developed conscience founded on empathy for others, shaming and blaming as manipulation tactics can be practiced rather successfully through pressing their guilt and shame buttons, and this can take the manipulator very far (Simon, 2020, pp. 126-128).

It is considered to be essential to single out the classification of manipulative tactics suggested by George K. Simon (2020, p. 133), which are closely connected with covert-aggression. According to the author there are a number of covertly aggressive (manipulative) actions, and some are more common in professional contexts than others. Simon believes that covert intimidation is accomplished through the application of several methods which are very helpful in subtly intimidating others. Quite effective are the following methods: singling the target out for special treatment (i.e. selective treatment); leaving the target to feel abandoned and alone if s/he does not play ball in the manner the manipulator wants (i.e. systematic exclusion or ostracizing); or subtly providing for pleasant rewards to come a person's way for compliance while stealthily imposing negative consequences for non-compliance (i.e. covert rewards and victimizing are methods of manipulation, very successfully practiced in different situations of life and political speech in particular). One thing is beyond suspicion for Simon: overt intimidation is not usually the manipulator's game (ibid., p. 134).

Another very effective manipulative tactic, according to Simon, is lying. Manipulators will not only lie to you, but also about you. They will also discreetly urge people to disseminate falsehoods about you in order to lower your status or gain an edge over you. Lying is one of the most obvious 
indicators of a personality disorder. And the degree of a flaw in a person's character is frequently most visible in how and why they lie. The most seriously disturbed personalities (e.g., psychopaths, sociopaths) are especially pathological in their lying in that they lie lavishly and without remorse, and without any apparent necessity or justification, i.e., when the truth would easily suffice or would seem of more practical benefit (ibid., p. 134).

Denial which the author refers to is aimed at impression management, and control. Many people misapprehend it for the ego-defense technique of denial. The manipulation and responsibility-evasion tactic of denial is of a literally unusual kind. Denial can be used to gain an advantage rather than to protect oneself. When provoked, some of the most fervent aggressors may push forward the most violent denials. When someone denies something, the amount of superficial conviction might cause doubt. And, when combined with the strategies of feigning confusion/ignorance and innocence, or playing the role of a victim, denial is frequently much more successful as a strategy. The thing is that when confronted with anything they have done to hurt you, characterimpaired people may claim they have no idea what you are talking about, appear confused, or otherwise indicate that their hands are clean. And if they are persuasive enough about this, given your own degree of vigilance, you could wind up feeling like the bad guy for suspecting them in the first place. That is why this strategy works so well. It is always a good idea to have your facts clear and your supporting documents close at hand. Even yet, a tenacious manipulator may cling to a narrative. When a manipulator initiates to play the role of a victim, sensitive and conscientious individuals cannot bear seeing anyone in pain or in a disadvantageous situation. And the most effective method to exploit someone's compassion and so influence them into doing something they would not otherwise do is to skillfully portray yourself as a victim of some tragic event or someone else's actions. This is a particularly effective trump card for manipulators to use when someone is aware of their schemes and suspects them of being the victim.

After familiarizing with different approaches to the study of manipulation, it will be useful to consider the following view by Shostrom. According to him, modern man is a manipulator and s/he learns the act of manipulation as a result of living in a market society. Manipulation is not unique to contemporary man, however, as Western culture has become more structured, as mass media has expanded, and as sophisticated means of promotion, persuasion, and marketing have emerged, the opportunities for manipulation have undoubtedly multiplied. 
And the author accepts the approach that the urge to control and be controlled is a key aspect of the manipulator's nature (Shostrom, 1967).

It is simple to note that some formulations stress the hidden non-violent character of manipulation, while others emphasize the manipulator's supremacy, and yet others emphasize the disparity between the initial and indoctrinated wants and intents. This is the result of insufficient research on the concept of manipulation. In this regard, researchers (linguists, psychologists and so on) are still faced with the challenge of selecting required and sufficient criteria for the definition of manipulation.

In his work Discourse and Manipulation van Dijk considers the researcher to be the one who can detect any sort of manipulation. It is mostly his responsibility because the manipulator himself will never admit that his influence on people is intentional and purposeful. Manipulative tactics, on the other hand, can be utilized unknowingly in some circumstances. This might occur when the speaker is attempting to solve his/her immediate communicative goal. In fact, a number of concepts may occur in speech that deserve special attention as they potentially suggest the violation of discursive authority and can be revealed through Critical Discourse Analysis (CDA). The concept of manipulation is frequently employed in a more impressionistic manner, and there is hardly any formal explanation of the structures and processes involved in manipulation. Most cases of manipulation, as we perceive it, occur through text and speaking, hence a discourse analytical approach is of great help. On the other hand, those being controlled are human beings, and this is generally done by manipulating their minds, thus, a cognitive account can also provide insight on the processes. However, a social approach is necessary too, as manipulation is a type of interactional discourse, and it involves power and power abuse (van Dijk, 2006, pp. 359-360).

According to Dr. Richard Paul and Dr. Linda Elder (2004, p. 20), manipulators can also use a variety of other tricks to attain their evil goals. One of these tricks is frequently referred to as pointing to another wrong. This is the case when the manipulator accuses the opponent of what $s /$ he is accused of. It particularly occurs in a situation when the manipulators are scolded and, having difficulty to find a way out, they flip the assault and use it to their advantage, making greater allegations against their opponents in order to compel them to defend themselves. Another trick is the unfounded alarm about a domino effect of undesirable things that will result in something horrible in the end. In other words, this trick is described as accusing the target of sliding a slippery slope: 
although action A of which the target is accused is not so awful, it may lead to action $\mathrm{B}$, which in its turn may possibly lead to $\mathrm{C}$ which is terrible.

Most individuals are awestruck by persons in positions of authority, prominence, or grandeur in general. Furthermore, many holy symbols (flags, religious imagery, sacred phrases, etc.) elicit strong connection and allegiance from individuals. Despite the fact that power, rank, and stature have little to do with wisdom and insight, people are captivated by individuals who hold such positions. Demagogues who effectively mislead people understand that the majority of people are easily duped in this manner. As a result, they wrap themselves in the flag and identify with authority, celebrity, or prestige (in any way they can). This includes hunting for experts and other knowledgeable people to back up their claims. This trick is defined by Dr. Richard Paul and Dr. Linda Elder (2004) as appealing to authority.

Buss et al. (1987, p. 1222) identify six types of manipulative methods used by manipulators to get things done the way they want:

1. Charm tactic. Manipulators employ charm techniques to obtain what they want by praising or charming their target in such a way that the latter does not suspect the manipulator of any wrongdoing. They are flattered, and this appeals to them, so they blindly follow the manipulator's instructions. This is a common strategy in which individuals act in this manner anytime they require or desire anything from the other.

2. Silent treatment. When manipulators ask/tell someone to do something but they are rejected, they employ the silent treatment method to force the individual to do what they are told or else they would be ignored. This can also be considered a kind of blackmail (if you don't do this, I won't talk to you).

3. Coercion tactic. Coercion method is employed when manipulators fail to get things done as intended because their target has rejected them. Thus, the manipulator must take efforts to attain his aim by demanding, yelling, shouting, and even verbally assaulting the victim as many times as necessary until their demands are satisfied and their goals are achieved. This may also be viewed as a type of psychological manipulation.

4. Reason tactic. When one needs others to follow, believe, or do what $\mathrm{s} /$ he says, reason tactic comes to help. The manipulator gives reasons why the target should do what $\mathrm{s} / \mathrm{he}$ is told to. As a result, he or she offers a very meaningful rationale to others while concealing the known facts from the listeners. Clearly, if s/he tells the full truth, many others would realize that this person is untrustworthy and that it would be foolish to follow in his/her 
footsteps. Thus, manipulators provide arguments that are enticing to others but are not fully true.

5. Regression tactic. Manipulators employ this type of strategy when they are first denied. If none of the other techniques succeeds, they will turn to this one. They make a funny expression and bother the target until he or she cannot take it any longer and has to perform what is asked to.

6. Debasement tactic. This tactic is employed when the manipulator has to degrade himself or behave in a very modest manner in order to get affection from the target and have him/her accomplish what he or she has requested them to do.

Linguistic manipulation from a political standpoint, i.e., the use of language to transmit a manipulative attitude in legal and political objectives that are not near to reality and truth, has a significant influence on people's political conscience. Manipulation in political speech conveys not just language components, but also historical, cultural, and psychological characteristics inherent in politics. Politicians construct and sustain the public's image of a savior, but in fact, they frequently lack a strong and realistic strategy for the country. They can only convince, influence, and impress the audience with their rhetorical speech and authoritative and strong phrases, which are in fact hollow. The audience is so desperate that the majority of them do not question the politician's ideas or plans; instead, they go with the flow to see what happens since they are so enthralled by the politician's speech (Handelman, 2009, p. 84).

Political discourse analysis, according to van Dijk (1997) and Dunmire (2012, p. 736), can either contain the text and the speech of politicians in openly political situations, or refer to a political vision of the discourse. Van Dijk divides political manipulative techniques into two categories: positive selfpresentation strategies and negative other-presentation strategies (Dijk, 2006, p. 373). Positive self-presentation is a strategy used by speakers to talk well about oneself, frequently using positive phrases and overall elevating themselves in the eyes of the audience. A speaker's use of negative otherpresentation is a strategy in which they seek to denigrate and tear down an opposing speaker. The initiator of such methods, which are sometimes regarded as underhanded or diversionary, often aims to lower the opposition's status in the eyes of the audience. 


\section{Conclusion}

Manipulation has become an indispensable part of our life, particularly in politics. Depending on the moment and context, politicians take use of their platform to appeal to public and gain their trust as leaders. However, they often to play to their audience, trying to charm them and through the employment of a variety of strategies and techniques influence them and seize control of the situation.

Considering different approaches to the study of manipulative strategies as a complex psycholinguistic concept we can assume that those tactics are generally implemented depending on the moment (situation) and context. However, all of these tactics and strategies are applied both directly and indirectly, and our understanding and interpretation of them depend on our feelings and interaction with people. On the one hand, there is no need for an individual to seek hidden meanings in words and ideas conveyed through speech in order to properly comprehend them if the meaning is supplied immediately and expressed directly, on the other hand, when communicating thoughts indirectly, using some strategies and delivering ambiguous signals, the interlocutor must be sensible enough to notice the hidden subtleties that are missing from the transmitted words.

It stands to reason that these manipulative strategies can be used in different registers including media, politics, social relations, etc. However, politics is assumed to have this high potential to unfold all those tricks that are platforms to appeal to voters in an election campaign, to demonstrate their power and presence during a crisis and so on. As far as media is concerned, we should note that we live with the overflow of media representations and the fact that media can take a variety of measures, employing many techniques and strategies to influence the audience in order to gain click bates and seize control of the situation is of utmost importance.

As a result, we came to the conclusion that manipulative strategies and tactics are defined in different works of theorists which in some of the cases go hand in hand to convey similar contextual interpretations. In the meantime, there are a number of semantic differences in terms of defining manipulation, and this will later allow us to conduct an analysis of concrete linguistic material to expose the manipulative nature of media-political discourse. 


\section{Notes}

In Oxford Learner's Dictionary (Retrieved from www.oxfordlearnersdiction aries.com/) manipulation is defined as "behaviour that controls or influences somebody/something, often in a dishonest way so that they do not realize it." A similar definition can be found in Cambridge Dictionary (Retrieved from https://dictionary.cambridge.org) which explains the term as "controlling someone or something to one's own advantage, often unfairly or dishonestly." According to Mirriam Webster Dictionary (Retrieved from https://merriamwebster.com), manipulation is interpreted as "treating or operating with or as if with the hands or by mechanical means especially in a skillful manner; managing or utilizing skillfully; controlling or playing upon by artful, unfair, or insidious means especially to one's own advantage."

\section{References}

Barnhille, A. (2014). What is manipulation? In Chr.Coons, \& M. Weber (Eds.), Manipulation: Theory and practice. Oxford Scholarship Online. DOI:10.1093/acprof:oso/9780199338207.003.0003

Buss, D. M., Gomes, M., Higgins, D.S., \& Lauterbach, K. (1987). Tactics of manipulation. Journal of Personality and Social Psychology, 52 (6), 1219-1229. Retrieved September 3, 2021 from https://cdn.la.utexas.edu/buss/files/2015/09/tactics_of_manipulation_1987_jpsp.pdf

Dunmire, P. L. (2012). Political discourse analysis: Exploring the language of politics and the politics of language. Language and Linguistic Compass, 6 (11), 735-751. Retrieved June 10, 2021 from https://www.researchgate.net/publication/263601538_Political_Discourse_Analysis_Ex ploring_the_Language_of_Politics_and_the_Politics_of_Language

Faden, R., \& Beauchamp, T. (1986). A history and theory of informed consent.

New York: Oxford University Press.

Gasparyan, S., Paronyan, Sh., \& Muradian G. (2019). The use and abuse of language in the legal domain. Montreal: Arod Books.

Handelman, S. (2009). Thought manipulation. The use and abuse of psychological trickery. Greenwood Publishing Group, Praeger, Retrieved August 2, 2021 from http://www.psicopolis.com/psicopedia/thoughtmanip.pdf

Ni, P. (2014). How to successfully handle manipulative people. Retrieved from http://www.nipreston.com/publications/excerpts/manipulativeexcerpt.pdf 
Ni, P. (2015). 14 signs of psychological and emotional manipulation. Psychology Today. Retrieved September 10, 2021 from https://www.scribd.com/document/288236905/14-Signs-of-

Psychological-and-Emotional-Manipulation-Psychology-Today

Raz, J. (1986). The morality of freedom. Oxford: Oxford University Press.

Richard, P., \& Elder, L. (2004). The thinker's guide to fallacies: the art of mental trickery and manipulation. Foundation for critical thinking. Retrieved September 10, 2021 from http://www.brahmakumaris.info/download/Cult\%20related/Fallacies.pdf

Shostrom, E.L. (1967). Man, the manipulator: the inner journey from manipulation to actualization. Canadian Journal of Counselling and Psychotherapy, 2(2), 128-129. Retrieved August 29, 2021from https://cjc-rcc.ucalgary.ca/ article/view/60576

Simon, G. K. (2020). Dealing with manipulative people. In M.Shoja et al., (Eds.). A Guide to the Scientific Career: Virtues, Communication, Research, and Academic Writing (pp.113-121), 123-137.

Sunstein, C. R. (2015). Fifty shades of manipulation. Harvard Library. Dash Harvard.Edu. Retrieved August 12, 2021 from https://dash.harvard.edu/ bitstream/handle/1/161499 47/ manipulation2_18.pdf

Van Dijk, T. (1997). What is political discourse analysis? Belgian Journal of Linguistics, 11 (1), 11-52. https://doi.org/10.1075/ bjl.11.03dij

Van Dijk, T. (2006). Discourse and manipulation, Discourse and Society, 17(2), 359-383. https://doi.org/10.1177/0957926506060250

Wilkinson, T. M. (2013). Nudging and manipulation. Political Studies, 61(2), 341-355. https://doi.org/10.1111/j.1467-9248.2012.00974.x

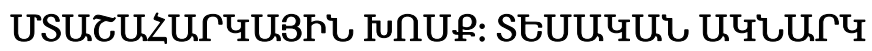

\section{Utiqu quuuqupjuis nuwqujki Zupnıpjnı\{juis}

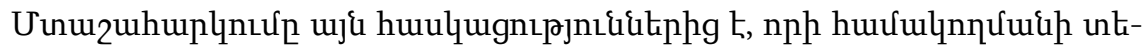

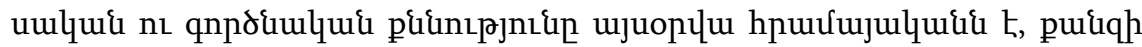

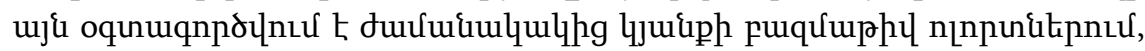

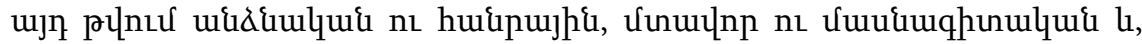

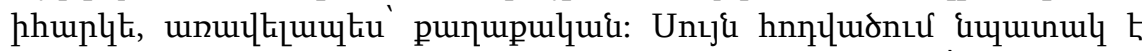

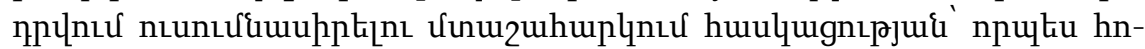

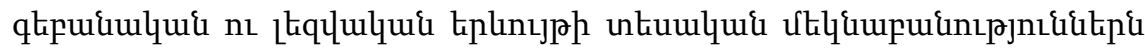




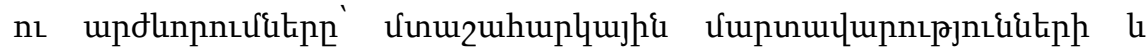

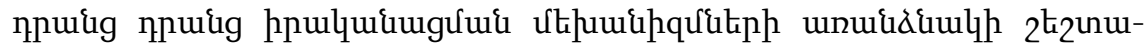

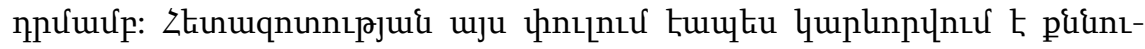

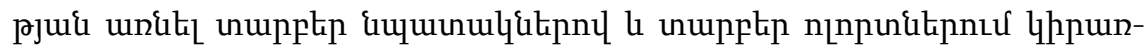

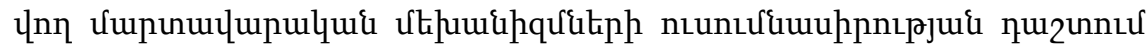

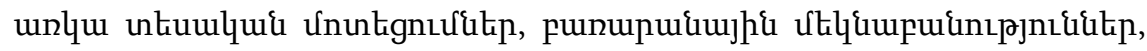

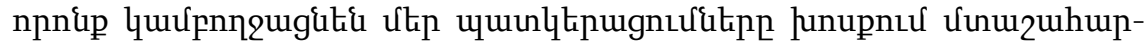

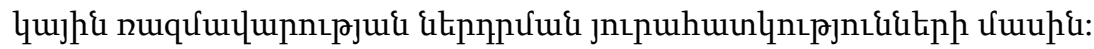

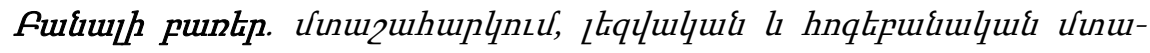

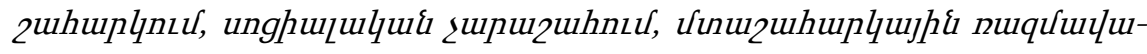

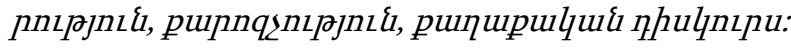

